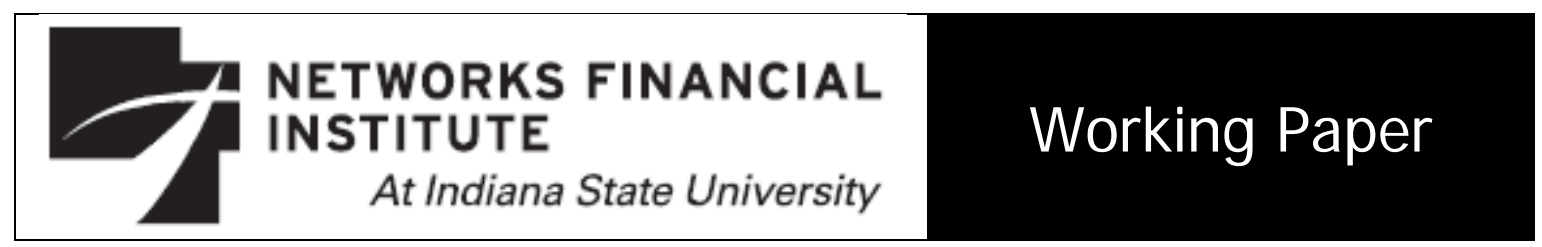

2009-WP-03

April 2009

\title{
Measuring the Efficiency of Financial Inputs for Entrepreneurship Lakshmi Balasubramanyan
}

Abstract: This study employs data on small businesses from the Office of Advocacy for the U.S. Small Business Administration, along with the Federal Deposit Insurance Corporation Call Report data for U.S. commercial banks. It examines the efficiency of the impact of the financial inputs on small business entrepreneurial output. This study provides a metric to capture financial input efficiency to the entrepreneurial process. The metric obtained from this analysis is useful for identification and adoption of best practices to enhance the efficiency of the entrepreneurial process.

About the Authors: Lakshmi Balasubramanyan is an Assistant Professor of Finance at Indiana State University. She received her Ph.D. in Agricultural, Environmental \& Regional Economics with her major fields being Finance and Production Economics from The Pennsylvania State University. Her research interests include international financial markets and institutions, production analysis, risk management, credit analysis in commercial banking and the efficiency of financial inputs to entrepreneurship. Her present research focuses on commercial bank size, risk variability and how cost inefficiency can be a signal of bank vulnerability.

Keywords: Financial services, Small business, Data envelopment analysis.

\section{JEL Classification: C60, D24, G21, L2}

The views expressed are those of the individual author and do not reflect official positions of Networks Financial Institute. Please address questions regarding content to Lakshmi Bal;asubramanyan at lakshmib@indstate.edu. Any errors or omissions are the responsibility of the author. NFI working papers and other publications are available on NFI's website (www.networksfinancialinstitute.org). Click "Research" and then "Publications/Papers." 


\section{Measuring the Efficiency of Financial I nputs for Entrepreneurship Lakshmi Balasubramanyan}

\section{Introduction}

The banking system and its role in influencing credit availability is a central question to the economics and the financial dynamics of entrepreneurship. In the United States, banks are the key institutional supplier of financial credit to small businesses. It is therefore important to understand how banks meet the needs of small businesses. Information on credit availability and the efficiency with which credit inputs are transformed into small business entrepreneurial output is crucial in determining the health and growth of small businesses in the United States economy. The Small Business and Micro Lending Report 2006-2007 points out that such information is crucial in signaling to small businesses about credit availability and lending institutions on the demand and supply for financial inputs and credit. ${ }^{1}$

Recent empirical research, in particular by Black and Strahan (2002); Cetorelli and Strahan (2006); Zarutskie (2006); and Bertrand et al. (2007), provide some insight into the issue of how changes in the structure of financial markets have impacted entrepreneurial activity, and subsequently, economic growth. It was found that increased bank competition and deregulation have resulted in higher borrowing and new firm formation. Mason and Harrison (2002) point out that policy makers need to remove barriers to credit in order for small firms to increase their willingness to invest. HoltzEakin et al. (1994a, 1994b) find that financial liquidity constraints exert a strong influence on the viability of entrepreneurial enterprises.

\footnotetext{
${ }^{1}$ Small Business Administration, Office of Advocacy, http://www.sba.gov/advo/research/chron.html Williams, V., \& Ou, C. (June 2008).
} 
While these studies have substantially increased our knowledge of the importance of financial inputs in entrepreneurial growth, a quantitative analysis to evaluate the efficiency of converting financial inputs into entrepreneurial outputs is still lacking. According to Barr et al. (2002), efficiency analysis can allow us to benchmark institutions, systems or processes to determine the relative performance or efficiency among competing entities or decision making entities. Through efficiency analysis, we can derive a numerical efficiency score that will allow us to rank the performance of each decision making entity. This then can allow us to compare productive efficiency, the levels of outputs relative to the levels of inputs, across different entities. A decision making entity that is productively efficient must maximize its outputs with a given level of input or alternatively minimize its inputs with a given level of output.

This study expands our understanding of impact of efficiency evaluation on assessing financing environments that promote entrepreneurial activities. It uses quantitative models to evaluate performance via benchmarking, and to further measure the impact of financial input cost and efficiency on entrepreneurship within midwestern states in the United States. We employ data on small businesses from the Office of Advocacy for the U.S. Small Business Administration along with the Federal Deposit Insurance Corporation (FDIC) Call Report data for United States commercial banks. In our analysis, we hypothesize that (a) states with the lowest level of small business employment, firm and establishment creation are the least efficient states in converting financial inputs to entrepreneurial output, (b) the scale and size of entrepreneurship in each of the midwest states determine their level of efficiency. We 
employ Data Envelopment Analysis, a quantitative tool, and examine the efficiency of the impact of financial input and cost on the small business output levels.

Our results indicate that states such as Iowa, Kansas and Nebraska have the lowest level of financial inputs and are the least efficient states. The states of Indiana, Michigan and Minnesota are the most efficient states. Though Indiana, Michigan and Minnesota do not have the highest level of inputs, they are the most efficient states with regard to small business output generation. The results also suggest that economies of scale play an important role in converting financial inputs to small business outputs. However, states such as Illinois and the Ohio exhibit decreasing returns to scale. These states have to reduce their expenses proportionately more in order to achieve an even greater level of efficiency.

The approach used in this paper provides a metric to capture financial input efficiency to the entrepreneurial process. The peer analysis that emerges from this quantitative approach is useful for identification and adoption of best practices to enhance financial input efficiency of the entrepreneurial process. Broadly, this research complements the existing body of work that studies the financial sector's role in driving economic growth. It adds an efficiency dimension to the issue of how financial sector inputs affect the entrepreneurial output of the economy.

The paper proceeds as follows: in the next section, we discuss the data and describe the credit related inputs and outputs. In Section 3 we describe the model and methodology following which we discuss the results. Section 5 concludes with a discussion on policy implications. 


\section{Data}

The data used in this study are from the Office of Advocacy for the United States Small Business Administration (SBA) along with the FDIC Call Report data for United States commercial banks. ${ }^{2}$ The SBA data are compiled based on data from the United States Census Bureau. Since the latest data in this set are for the year 2006, this paper analyzes entrepreneurial activity for this year 2006 in the U.S. midwestern states of Illinois, Indiana, Iowa, Kansas, Michigan, Minnesota, Missouri, Nebraska, Ohio and Wisconsin. Appendix 1 lists all the data used in this study.

\subsection{Credit Related Inputs}

In this study, financial inputs can be broadly categorized as institutional and income-related variables. Total number of offices is one measure representative of institutional and structural strength of the commercial bank industry. It is also indicative of the degree of competition in these states. Information on net income and number of employees is found in the income statements. Illinois has the largest number of bank offices. It had 4,448 offices in 2006, while Ohio and Michigan had 3,582 and 2,918 offices, respectively. However, the ranking for the total number of bank employees does not correspond with the number of bank offices. Ohio has the largest number of bank employees with 277,228. The second largest state is Illinois followed by Michigan with 56,890 and 277,228 employees respectively.

The income-statement provides information on total salary expense, fixed assets, premises, interest expense and non-interest expense. As Barr et al. (2002) point out,

\footnotetext{
2 Data Source:

SBA Hhttp://www.sba.gov/advo/research/data.html

FDIC Hhttp://www2.fdic.gov/SDI/SOB/
} 
banks allocate resources and control internal processes by managing their employees, facilities, expenses to maximize total income. The best practice banks are on the efficiency frontier and are deemed efficient. Banks that use too much input to produce a given level of entrepreneurial output relative to its peers are considered inefficient.

Figure 1 provides a plot of inputs. Ohio ranks the highest in total salary expense, cost of fixed assets and premises, interest expense and non-interest expense. Ohio is followed by Illinois and then by Michigan. The states exhibiting the lowest inputs are Nebraska, Kansas and Iowa. Minnesota, Missouri, Wisconsin and Indiana can be considered median states that have input size lying between the highest and lowest input states. Table 1 categorizes the states based on the size of input usage.

\section{$2.2 \quad$ Entrepreneurial Output}

The SBA database provides data on entrepreneurial output. The outputs are employer firms, establishments, employment and annual payroll for each state in the U.S. In this study, the number of firms, number of establishments, employment and payroll generation are reflective of entrepreneurial output. These variables measure entrepreneurial activity and business creation. In the dataset, a firm is defined as the aggregation of all establishments owned by a parent company (within a geographic location and/or industry) that have some annual payroll. A firm may be located in one or more places. Total employment is the total size of people employed in all the firms within the state. Annual payroll is the total payroll outlay for each state in a given year. Based on Figure 2, we find that Illinois has the highest number of firms and establishments. It also has the largest amount of employment and payroll generated. In 2006, Illinois had 262,870 firms and 321,356 establishments. It generated 5.4 million jobs and \$2.3 billion 
in annual payroll. Ohio ranks as the second largest state in terms of entrepreneurial output, having 207,768 firms and 269,914 establishments. It generated 4.8 million jobs and $\$ 1.8$ billion in annual payroll. The state of Michigan is the third largest midwestern state to generate entrepreneurial output. In 2006, Michigan created 190,411 firms and 235,750 establishments. It generated 3.8 million jobs and $\$ 1.51$ billion in annual payroll. Figure 2 provides a plot of entrepreneurial output in the year 2006. Illinois has the highest entrepreneurial output and is followed by Ohio and Michigan. The states exhibiting the lowest entrepreneurial output are Nebraska, Kansas and Iowa. Minnesota, Missouri, Wisconsin and Indiana are median states that have output generation lying between the highest and lowest output states. Table 2 categorizes the states based on the size of small business entrepreneurial output.

\section{Model and Methodology}

In order to quantitatively evaluate the efficiency of financial inputs being transformed to entrepreneurial outputs, we employ Data Envelopment Analysis (DEA) model. We consider the financial intermediation role of a bank, the bank's income and institutional structure as inputs to the entrepreneurial process. We then compute a scalar measure of efficiency. ${ }^{3}$ The multi-input, multi-output DEA model measures the transformational efficiency, considered as a proxy for the quality and ability of each midwestern state to harness the financial environment, structure and inputs to create entrepreneurial outputs relative to its peer midwestern states.

Each of the midwestern states is considered as decision-making units (DMUs) in allocating financial resources towards the entrepreneurial process. As Barr (1993) points out, the efficient DMUs are the states that ensure financial structure and climate

\footnotetext{
${ }^{3}$ In this paper, we closely follow the approach taken by Barr et al. (1993).
} 
conducive for entrepreneurship. Loans are effectively channeled towards business

creation and banks are well capitalized with a strong asset-base to meet the

entrepreneurial challenges met in the state. Therefore, efficient states are states that have

utilized their financial structure, maximized their income by keeping expenses low. These states have been successful in making loans to worthwhile business opportunities with a lower probability of default. The most efficient midwestern states are those that have generated sufficient entrepreneurial output with minimum waste, expense and have made creditworthy loans relative to peer states. Chart 1 provides a descriptive summary of the model.

\section{Financial structure and entrepreneurial quality of each state}

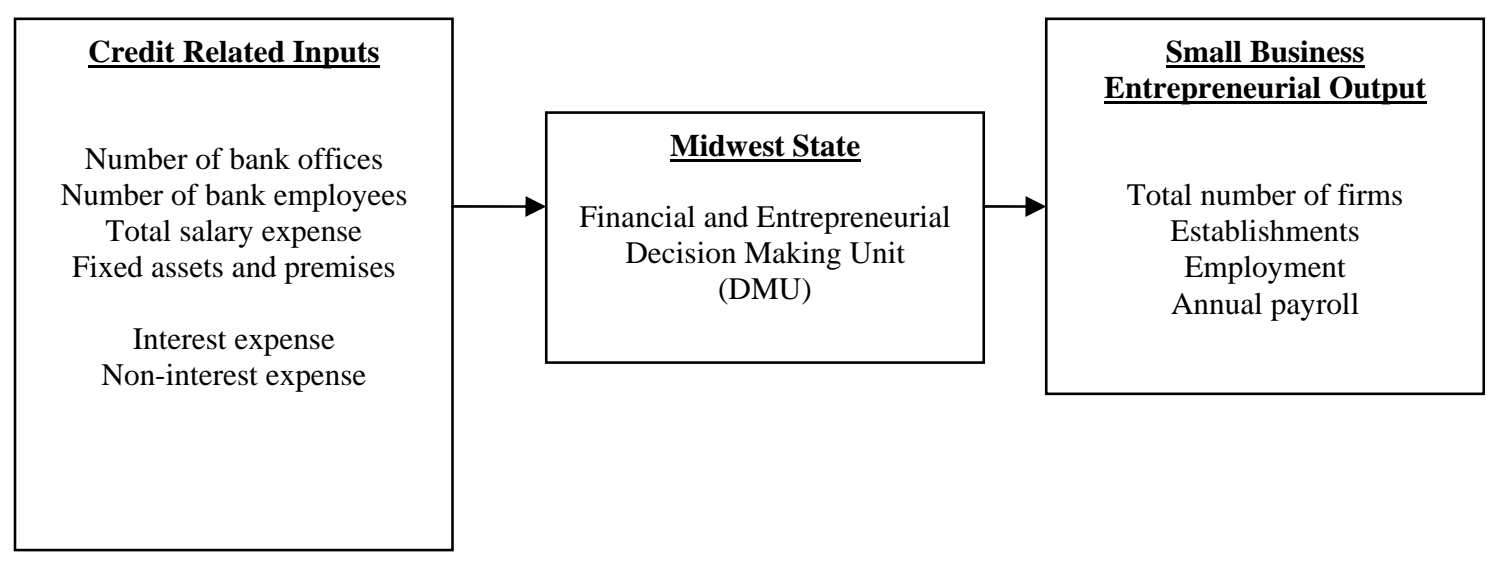

\subsection{Data Envelopment Analysis}

In this section, we describe the non-parametric mathematical programming approach to estimating an efficiency frontier. Charnes et al. (1978) called this the Data Envelopment Analysis (DEA) approach. In our dataset, we have $M$ inputs $(M=8)$ and $N$ outputs $(N=4)$ for each of the $P$ midwestern states $(P=10)$. For the $i$-th state, its inputs and outputs are represented by column vectors $x_{i}$ and $y_{i}$. The $M^{\prime} P$ input matrix $X$ and $N^{\prime} P$ output matrix $Y$ represent the data for all 10 states. As Battese and Coelli 
(2006) explain, the purpose of the DEA is to construct a non-parametric envelopment frontier over the data points such that all observed points lie on or below the production frontier

The DEA is best represented in a ratio form. For each of the states, we obtain a ratio of all outputs over inputs. This is expressed as $\frac{u \Phi_{i}}{v \phi_{i}}$. The vector $u$ is a vector of output weights whose dimension is $N^{\prime} 1$. The vector $v$ is a vector of input weights whose dimension is $M^{\prime} 1$. The objective of the linear-programming problem is to find values of $u$ and $v$ that maximize the efficiency measure of each and every state. The problem is set up as follows:

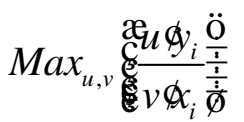

$$
\begin{aligned}
& \text { s.t } \\
& \frac{u \oiint_{i}}{v \mathbb{K}_{i}} £ 1, i=1,2, \ldots \ldots ., P \\
& u, v^{3} 0
\end{aligned}
$$

Since this set up can result in an infinite number of solutions, we impose an additional constraint $v \Phi_{i}=1$. With constraint in place, the problem can be set up as a multiplier linear programming form as:

$$
\begin{aligned}
& \operatorname{Max}_{u_{1}, v}\left(u_{1}^{\prime} y_{i}\right) \\
& \text { s.t } \\
& v_{1}^{\prime} x_{i}=1 \\
& u_{1}^{\prime} y_{i}-v_{1}^{\prime} x_{i} £ 0, i=1,2, . ., P \\
& u_{1}, v_{1}{ }^{3} 0
\end{aligned}
$$


Using the duality in linear programming, the envelopment form of (2) can be set up according to Battese and Coelli (2006) as:

$$
\begin{aligned}
& \operatorname{Min}_{a, b} a \\
& \text { s.t } \\
& -y_{i}+Y b^{3} \quad 0 \\
& a x_{i}-X b^{3} \quad 0 \\
& b^{3} 0
\end{aligned}
$$

where $a$ is a scalar and $b$ is a $P^{\prime} 1$ vector of constants. The value of $a$ obtained will be the efficiency score for the $i$-th midwestern state. The value of $a$ is less than or equals to 1. If $a=1$, it implies that the state is an efficient state according to Farrell (1957). The problem in (3) is solved $P$ number of times, one for each state in the sample, and yielded an efficiency score $a$ for each state. However, there is an issue that needs to be addressed about the Farrell measure. When we consider multiple inputs and outputs, there is the issue of input and output slacks. ${ }^{4}$ In order to obtain an accurate indication of efficiency for each state in the DEA analysis, a second stage linear programming problem is identified. This problem is defined as:

$$
\begin{aligned}
& \operatorname{Min}_{b, S, T}-\left(N_{1} S+M_{1} T\right) \\
& \text { s.t } \\
& -y_{i}+Y b-S^{3} 0 \\
& a x_{i}-X b-S^{3} 0 \\
& \begin{array}{llll}
b^{3} & 0, S^{3} & 0, T^{3} & 0
\end{array}
\end{aligned}
$$

where $S$ is a $M^{\prime} 1$ vector of output slacks and $T$ is a $K^{\prime} 1$ vector of input slacks, and $N_{1}$ and $M_{1}$ are $N^{\prime} 1$ and $M^{\prime} 1$ vectors of ones. The value of $a$ is obtained from the

\footnotetext{
${ }^{4}$ The piece-wise linear form of DEA computation can cause a few difficulties. If the piece-wise linear frontier lies parallel to the input (x) and output (y) axes, you could reduce the input to obtain the same amount of output. This is known as an input slack. A second stage linear programming problem is solved to minimize the slacks.
} 
first stage results. The second stage linear programming problem is also solved for each state.

\section{4. $\quad$ Results}

Figure 3 and Table 3 provide a summary of the results for the input-oriented DEA model for each of the ten midwestern states. The efficiency score $\alpha$ indicates which states are efficient in transforming financial inputs to entrepreneurial outputs. The states of Indiana, Minnesota and Michigan show an efficiency score of 1 and are deemed 100\% efficient in transforming financial inputs to small business entrepreneurial output. All three efficient states operate under constant returns to scale. This implies that when inputs are increased by a factor $n$, outputs increase exactly by factor $n$.

The states of Nebraska, Kansas and Iowa have an efficiency score of $0.651,0.734$ and 0.777 respectively. Relative to the other states, these states are the least efficient. Nebraska exhibits the highest level of inefficiency. It exhibits a 34.9\% efficiency deficit. Kansas and Iowa exhibits approximately 26.6\% and 22.3\% efficiency deficit, respectively. There is substantial capacity for improvement in these states. These three states also experience increasing returns to scale; this implies that there are substantial economies of scale that can be reaped in these states. When financial inputs increase by a factor $n$, entrepreneurial outputs increase by more than a factor $n$ due to increasing returns to scale.

Our results show that the states of Illinois, Ohio, Missouri and Wisconsin have efficiency scores of $0.886,0.934,0.808$ and 0.91 , respectively. Ohio and Wisconsin exhibit approximately 7\% and 9\% efficiency deficits while the states of Illinois and Missouri experience 11\% and 19\% deficit in efficiency. Further, the results show that the 
states of Illinois, Ohio and Missouri experience decreasing returns to scale. This means when inputs increase by a factor $n$, outputs increase by less than a factor $n$.

The input-oriented DEA efficiency scores itself do not reflect the process of attaining efficiency; the score is a static number that captures the current level of efficiency. In order to obtain information that will allow states to alter their inputs to achieve the desired entrepreneurial output targets, the second stage DEA analysis is necessary. This analysis incorporates information on how efficient input and output targets can be attained. This information can serve as inputs in the planning process by state and federal government in promoting small business entrepreneurship through increased financial inputs and access to financial inputs.

The results of the second stage DEA analysis are shown in Figures 4 and 5 and Table 4. Figure 4 shows the percentage reduction in financial inputs to attain frontier efficiency whereas Figure 5 shows the percentage increase in entrepreneurial output as a result of efficient levels of input usage. Table 4 presents the percentage changes required for the state to attain efficiency. ${ }^{5}$

In order for the state of Illinois to attain efficiency, it can increase the number of small business firms by $8.5 \%$, increase the number of small business establishments by $8 \%$ and raise employment by $6.1 \%$. Alternatively, it would have to downsize the number of commercial bank offices and bank employment input by $11.4 \%$ and $14.7 \%$ respectively. Further, Illinois would have to reduce its salary expenses, premises and fixed asset expenses, interest expense and non-interest expense by 34.7\%, 24.9\%, 58.4\% and $39.1 \%$ respectively.

\footnotetext{
${ }^{5}$ Percentage change refers to the percentage difference between actual inputs (outputs) and efficiency target inputs (outputs)
} 
Utilizing the same analysis as above, Ohio could increase the number of small business firms by $16.52 \%$, the number of small business establishments by $9.12 \%$ and total small business payroll by $11.38 \%$. Alternatively, it can reduce its salary expense by 90.76\%, premises and fixed asset expense by $91.91 \%$, interest expense by $93.20 \%$ and non-interest expense by $91.95 \%$.

Similarly, the state of Wisconsin could attain efficiency by reducing its bank employee input by $15.06 \%$, salary expense by $16.18 \%$, premises and fixed assets by 8.99\%, interest expense by $53.56 \%$ and non-interest expense by $25.64 \%$. Alternatively, Wisconsin can increase the efficient number of small business firms and establishments by $1.08 \%$ and $1.17 \%$. This will result in a small business payroll increase of $7.21 \%$.

Nebraska will attain efficiency if it increases small business establishments, employment and payroll by $1.14 \%, 10.97 \%$ and $33.15 \%$ respectively. Alternatively, efficiency is attainable if the state decreases salary expenses by $45.72 \%$, premises and fixed assets by $40.44 \%$, interest expense by $34.89 \%$ and non-interest expense by $54.96 \%$.

By reducing its salary expenses by $22.01 \%$, fixed assets and premises by $19.20 \%$, interest expense by $30.17 \%$ and non-interest expense $27.18 \%$, the state of Missouri could attain efficiency. Iowa can increase its small business employment by $13.61 \%$ and payroll output by $22.65 \%$ or alternatively reduce its bank expenses by 26 to $32 \%$. Likewise, Kansas can increase its small business employment by $18.36 \%$ and payroll by $24.54 \%$ or reduce its salary expenses by $32.64 \%$, fixed assets and premises by $29.55 \%$, interest expense by $26.56 \%$ and non-interest expense by 33.09\%. 


\section{Policy Implications and Conclusion}

We find that efficiency based analysis helps to empirically evaluate the efficiency of financial inputs in producing small business outputs. The efficiency scores for each of the states can be used as a planning metric. State governments can use these efficiency scores and target outputs. Further, the scores can be used to assess the financing environments that promote entrepreneurial activities. The knowledge of how efficiently financial inputs are meeting small business credit needs is critical in understanding the health and growth of small businesses. The study can serve as a useful input for the design and implementation of public policies pertaining to the efficiency of financial inputs to the entrepreneurial enterprise.

By adopting a performance evaluation and benchmarking approach, this paper serves as an input metric to address imperative questions on policies geared towards enhancing entrepreneurship and achieving efficient entrepreneurship at the state level. This study provides us with answers to determine whether the entrepreneurship process is efficient. It suggests that the financial input market can evolve to promote efficient entrepreneurship. Policy climate can be adjusted to ensure efficient entrepreneurship. State level benchmarks can be used to achieve entrepreneurial efficiency and growth gains that could be obtained by moving to greater efficiency. 


\section{References}

Barr, R. S., Killgo, K. A., Siems, T. F., \& Zimmel, S. (2002). Evaluating the productive efficiency and performance of U.S. commercial banks. Managerial Finance, 28(8), 3-25.

Barr, R. S., Seiford, L. M., \& Siems, T. F. (1993). An envelopment-analysis approach to measuring the managerial efficiency of banks. Annals of Operations Research, 45, 1-19.

Bertrand, M., Schoar, A., \& Thesmar, D. (2007). Banking deregulation and the industry structure. The Journal of Finance, 62(2).

Black, S. E., \& Strahan, P. E. (2002). Entrepreneurship and bank credit availability. The Journal of Finance, 57(6), 2807-2833.

Cetorelli, N., \& Strahan, P. E. (2006). Finance as a barrier to entry: Bank competition and industry structure in local U.S. markets. The Journal of Finance, 61(1).

Charnes, A., Cooper, W. W., \& Rhodes, E. (1978). Measuring the efficiency of decision making units. European Journal of Operational Research, 2, 429-444.

Coelli, T. J., Prasada Rao, D. S., O'Donnell, C. J., \& Battese, G. E. (2005). An Introduction to Efficiency and Productivity Analysis (2nd ed.).

Farrell, M. J. (1957). The measurement of productive efficiency. Journal of the Royal Statistical Society, A(120), 251-281.

Holtz-Eakin, D., Joulfaian, D., \& Rosen, H. S. (1994). Sticking it out: Entrepreneurial survival and liquidity constraints. Journal of Political Economy, 102(1).

Holtz-Eakin, D., Joulfaian, D., \& Rosen, H. S. (Summer 1994). Entrepreneurial decisions and liquidity constraints. RAND Journal of Economics, 25(2).

Mason, C., \& Harrison, R. (2002). Barriers to investment in the informal venture capital sector. Entrepreneurship \& Regional Development, 14, 271-287.

Williams, V., \& Ou, C. (June 2008), Small Business and Micro Business Lending in the United States for Data Years 2006 - 2007 (No. 327). U.S. Small Business Administration, Office of Advocacy, Office of Education Research.

Zarutskie, R. (2006). Evidence on the effects of bank competition on firm borrowing and investment. Journal of Financial Economics, 81, 503-537. 
Figure 1: Plot of inputs for 2006
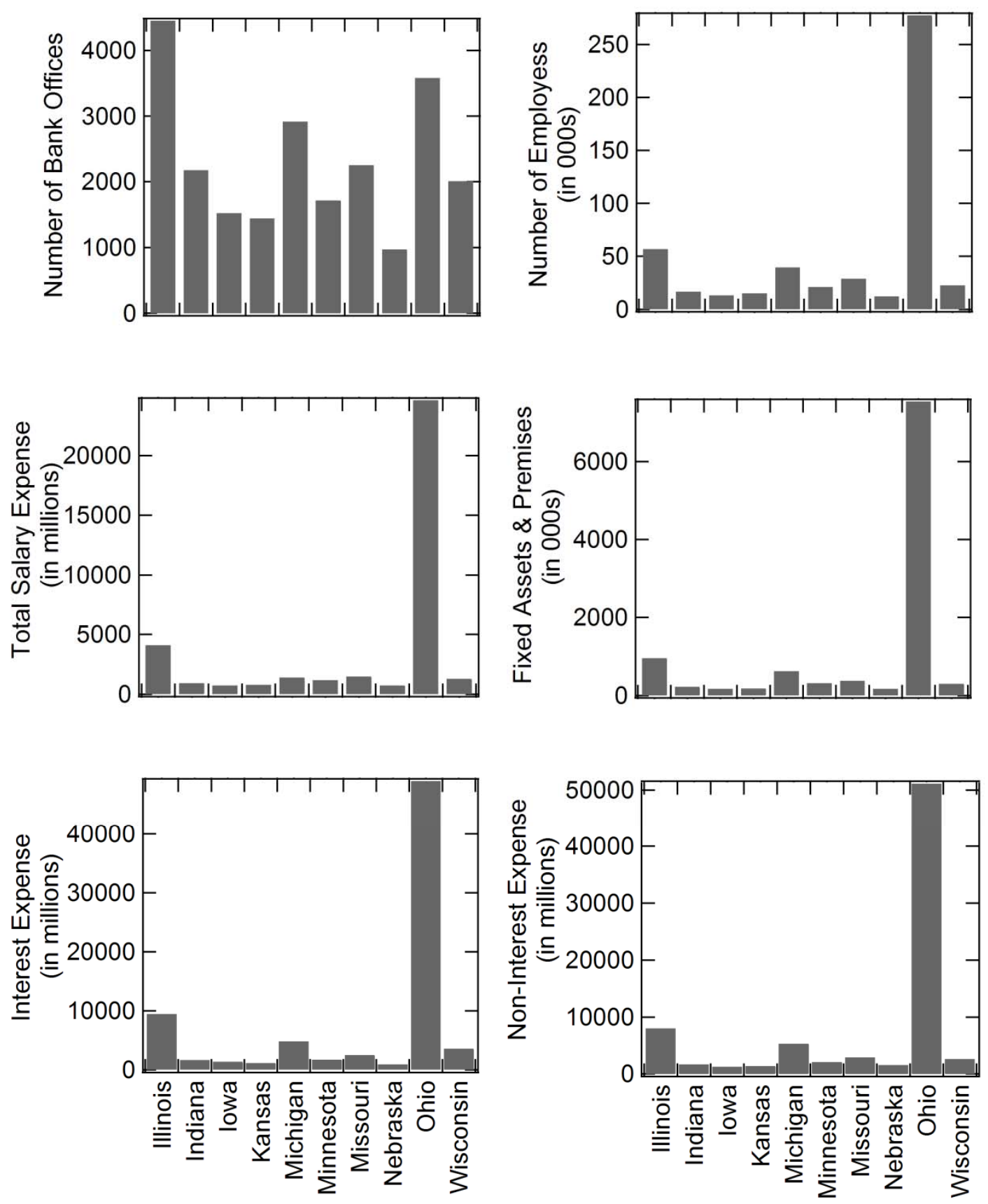

Table 1: Categorization of midwest states based on size of input usage

\begin{tabular}{ccc}
\hline Highest Level Input & Median Level Input & Lowest Level Input \\
\hline Ohio & Indiana & Nebraska \\
Illinois & Minnesota & Kansas \\
Michigan & Missouri & Iowa \\
& Wisconsin & \\
\hline
\end{tabular}


Figure 2: Plot of entrepreneurial outputs 2006
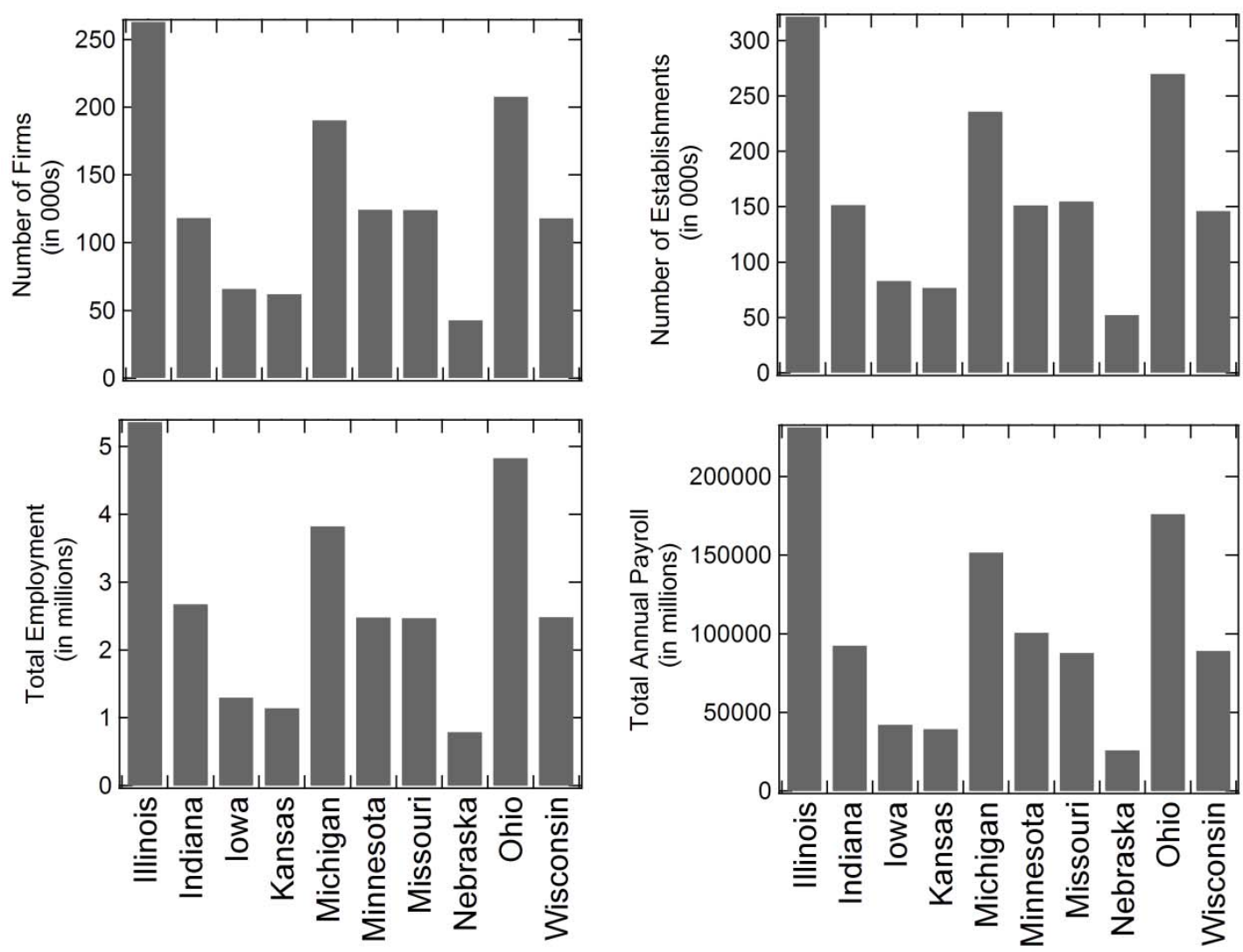

Table 2: Categorization of midwest states based on size of small business entrepreneurial output

\begin{tabular}{ccc}
\hline Highest Level Output & Median Level Output & Lowest Level Output \\
\hline Illinois & Indiana & Nebraska \\
Ohio & Minnesota & Kansas \\
Michigan & Missouri & Iowa \\
& Wisconsin & \\
\hline
\end{tabular}


Figure 3: Plot of efficiency score

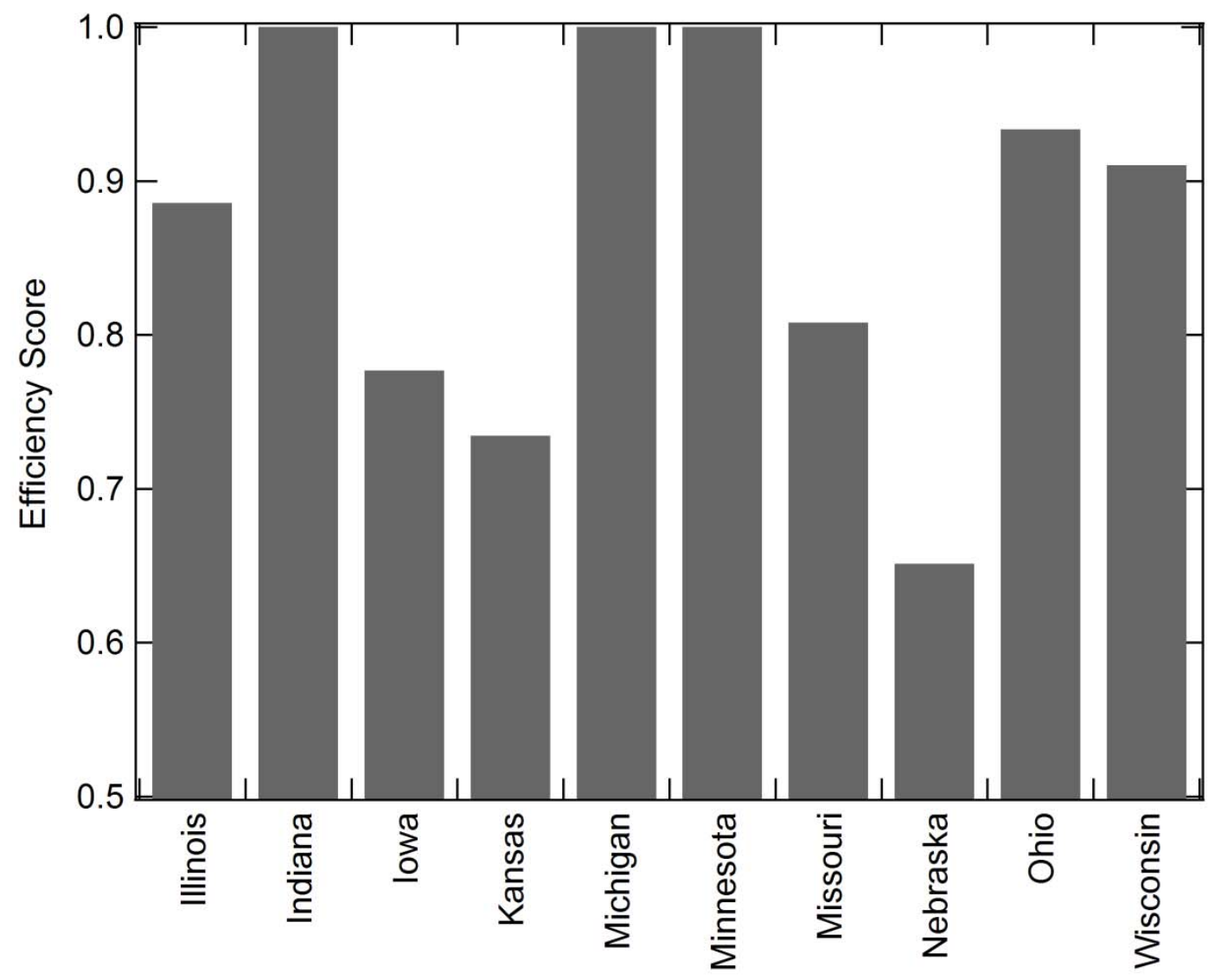

Table 3: Efficiency scores, percentage efficiency difference and returns to scale

\begin{tabular}{lcccc}
\hline State & Efficiency Score $\alpha$ & Percentage & Percentage Efficiency Difference & Returns to Scale \\
\hline Illinois & 0.886 & 88.6 & 11.41 & Decreasing \\
Indiana & 1.000 & 100.0 & 0.00 & Constant \\
Iowa & 0.777 & 77.7 & 22.34 & Increasing \\
Kansas & 0.734 & 73.4 & 26.56 & Increasing \\
Michigan & 1.000 & 100.0 & 0.00 & Constant \\
Minnesota & 1.000 & 100.0 & 0.00 & Constant \\
Missouri & 0.808 & 80.8 & 19.20 & Decreasing \\
Nebraska & 0.651 & 65.1 & 34.89 & Increasing \\
Ohio & 0.934 & 93.4 & 6.65 & Decreasing \\
Wisconsin & 0.910 & 91.0 & 8.99 & Increasing \\
\hline
\end{tabular}


Figure 4: Percentage reduction in inputs to attain frontier efficiency
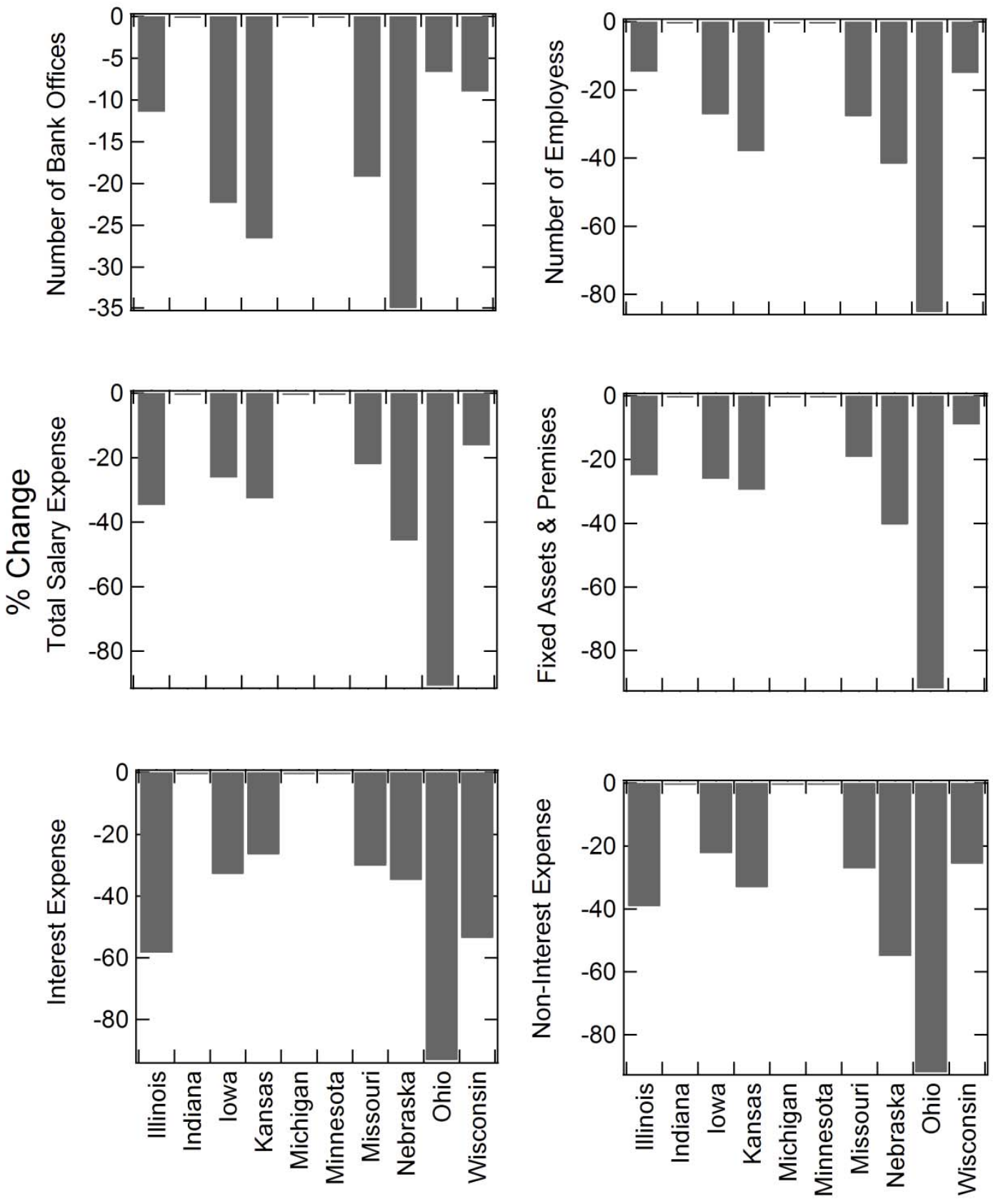

Figure 5: Percentage increase in outputs to attain frontier efficiency 

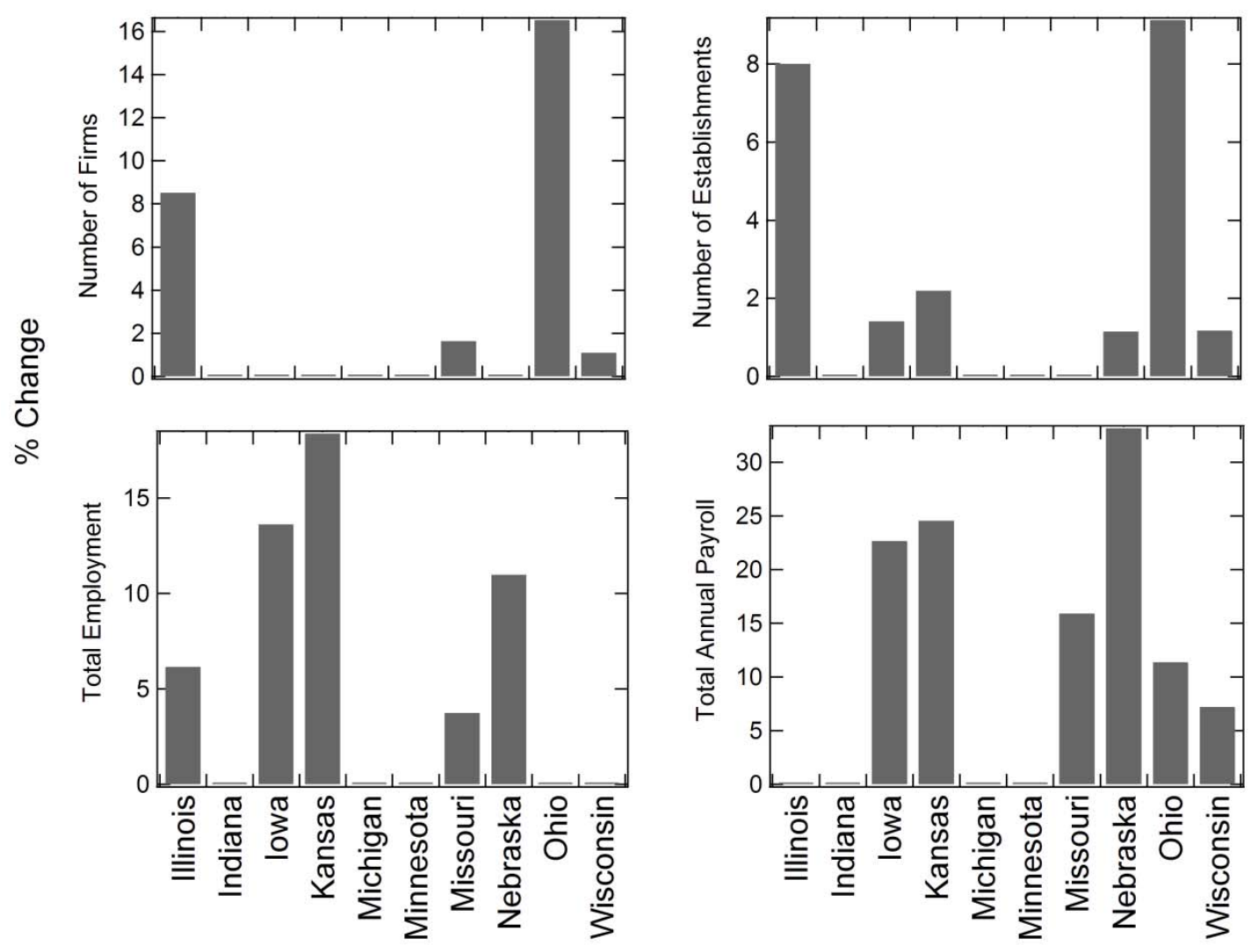

Table 4: Efficiency scores, percentage efficiency difference and returns to scale

\begin{tabular}{|c|c|c|c|c|c|c|c|c|c|c|}
\hline \multicolumn{7}{|c|}{ Percentage reduction in inputs to attain frontier efficiency } & \multicolumn{4}{|c|}{ Percentage increase in outputs to attain frontier efficiency } \\
\hline DMU Name & office & empinput & salaryexp & premises & intexp & nonintexp & firms & estab & 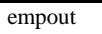 & pay \\
\hline Illinois & $-11.41 \%$ & $-14.70 \%$ & $-34.74 \%$ & $-24.92 \%$ & $-58.42 \%$ & $-39.14 \%$ & $8.52 \%$ & $8.00 \%$ & $6.14 \%$ & $0.00 \%$ \\
\hline Indiana & $0.00 \%$ & $0.00 \%$ & $0.00 \%$ & $0.00 \%$ & $0.00 \%$ & $0.00 \%$ & $0.00 \%$ & $0.00 \%$ & $0.00 \%$ & $0.00 \%$ \\
\hline Iowa & $-22.34 \%$ & $-27.16 \%$ & $-26.15 \%$ & $-26.11 \%$ & $-32.88 \%$ & $-22.34 \%$ & $0.00 \%$ & $1.41 \%$ & $13.61 \%$ & $22.65 \%$ \\
\hline Kansas & $-26.56 \%$ & $-38.03 \%$ & $-32.64 \%$ & $-29.55 \%$ & $-26.56 \%$ & $-33.09 \%$ & $0.00 \%$ & $2.19 \%$ & $18.36 \%$ & $24.54 \%$ \\
\hline Michigan & $0.00 \%$ & $0.00 \%$ & $0.00 \%$ & $0.00 \%$ & $0.00 \%$ & $0.00 \%$ & $0.00 \%$ & $0.00 \%$ & $0.00 \%$ & $0.00 \%$ \\
\hline Minnesota & $0.00 \%$ & $0.00 \%$ & $0.00 \%$ & $0.00 \%$ & $0.00 \%$ & $0.00 \%$ & $0.00 \%$ & $0.00 \%$ & $0.00 \%$ & $0.00 \%$ \\
\hline Missouri & $-19.20 \%$ & $-27.75 \%$ & $-22.01 \%$ & $-19.20 \%$ & $-30.17 \%$ & $-27.18 \%$ & $1.62 \%$ & $0.00 \%$ & $3.73 \%$ & $15.91 \%$ \\
\hline Nebraska & $-34.89 \%$ & $-41.69 \%$ & $-45.72 \%$ & $-40.44 \%$ & $-34.89 \%$ & $-54.96 \%$ & $0.00 \%$ & $1.14 \%$ & $10.97 \%$ & $33.15 \%$ \\
\hline Ohio & $-6.65 \%$ & $-85.15 \%$ & $-90.76 \%$ & $-91.91 \%$ & $-93.20 \%$ & $-91.95 \%$ & $16.52 \%$ & $9.12 \%$ & $0.00 \%$ & $11.38 \%$ \\
\hline Wisconsin & $-8.99 \%$ & $-15.06 \%$ & $-16.18 \%$ & $-8.99 \%$ & $-53.56 \%$ & $-25.64 \%$ & $1.08 \%$ & $1.17 \%$ & $0.00 \%$ & $7.21 \%$ \\
\hline
\end{tabular}


Appendix 1: Data employed in this study for the year 2006

\begin{tabular}{|c|c|c|c|c|c|c|c|c|c|c|}
\hline & Illinois & Indiana & Iowa & Kansas & Michigan & Minnesota & Missouri & Nebraska & Ohio & Wisconsin \\
\hline \multicolumn{11}{|c|}{ Entrepreneurial Output } \\
\hline Firms & 262,870 & 118,159 & 65,829 & 61,902 & 190,411 & 124,237 & 124,120 & 42,649 & 207,768 & 117,917 \\
\hline Establishments & 321,356 & 151,283 & 82,698 & 76,446 & 235,750 & 151,150 & 154,546 & 51,906 & 269,914 & 145,836 \\
\hline Employment & $5,357,466$ & $2,673,010$ & $1,295,258$ & $1,142,680$ & $3,819,537$ & $2,476,354$ & $2,468,035$ & 789,231 & $4,825,510$ & $2,482,281$ \\
\hline Annual Payroll ('000s) & $231,106,738$ & $92,334,415$ & $42,096,840$ & $39,251,387$ & $151,504,380$ & $100,645,287$ & $87,735,211$ & $25,743,159$ & $176,074,839$ & $89,006,820$ \\
\hline \multicolumn{11}{|c|}{ Credit Related Inputs } \\
\hline \multicolumn{11}{|c|}{ Institution and Structure } \\
\hline Total Offices & 4,448 & 2,173 & 1,520 & 1,439 & 2,918 & 1,716 & 2,253 & 972 & 3,582 & 2,008 \\
\hline Number of employees & 56,890 & 16,753 & 13,069 & 14,976 & 39,571 & 21,133 & 29,027 & 11,976 & 277,228 & 22,552 \\
\hline \multicolumn{11}{|l|}{ Income Condition } \\
\hline Salary Expenses & $4,110,781$ & 925,625 & 712,286 & 761,475 & $1,385,487$ & $1,168,379$ & $1,486,524$ & 711,206 & $24,634,128$ & $1,263,196$ \\
\hline Fixed Assets and Premises & 956,805 & 218,160 & 170,489 & 179,207 & 617,498 & 312,862 & 378,917 & 169,529 & $7,534,458$ & 300,589 \\
\hline Interest Expense & $9,442,561$ & $1,621,628$ & $1,346,370$ & $1,157,647$ & $4,798,165$ & $1,709,809$ & $2,485,150$ & 900,870 & $49,027,420$ & $3,528,869$ \\
\hline Non-interest expense & $7,963,098$ & $1,673,524$ & $1,224,475$ & $1,385,487$ & $5,330,006$ & $2,110,677$ & $2,876,520$ & $1,548,693$ & $51,071,957$ & $2,572,979$ \\
\hline
\end{tabular}

